\title{
Attention Determines Contextual Enhancement versus Suppression in Human Primary Visual Cortex
}

\author{
Anastasia V. Flevaris and Scott 0. Murray \\ Department of Psychology, University of Washington, Seattle, Washington 98195
}

Neural responses in primary visual cortex (V1) depend on stimulus context in seemingly complex ways. For example, responses to an oriented stimulus can be suppressed when it is flanked by iso-oriented versus orthogonally oriented stimuli but can also be enhanced when attention is directed to iso-oriented versus orthogonal flanking stimuli. Thus the exact same contextual stimulus arrangement can have completely opposite effects on neural responses - in some cases leading to orientation-tuned suppression and in other cases leading to orientation-tuned enhancement. Here we show that stimulus-based suppression and enhancement of fMRI responses in humans depends on small changes in the focus of attention and can be explained by a model that combines feature-based attention with response normalization.

Key words: feature-based attention; normalization; primary visual cortex; surround suppression

\section{Significance Statement}

Neurons in the primary visual cortex (V1) respond to stimuli within a restricted portion of the visual field, termed their "receptive field." However, neuronal responses can also be influenced by stimuli that surround a receptive field, although the nature of these contextual interactions and underlying neural mechanisms are debated. Here we show that the response in V1 to a stimulus in the same context can either be suppressed or enhanced depending on the focus of attention. We are able to explain the results using a simple computational model that combines two well established properties of visual cortical responses: response normalization and feature-based enhancement.

\section{Introduction}

Responses of neurons in primary visual cortex (V1) depend on stimulus context. The response to an oriented stimulus can be suppressed when it is flanked by iso-oriented stimuli compared with orthogonally oriented stimuli (Blakemore and Tobin, 1972; DeAngelis et al., 1994; Li and Li, 1994; Sillito et al., 1995; Walker et al., 1999; Cavanaugh et al., 2002; Shushruth et al., 2012). This orientation-tuned surround suppression is believed to reflect inhibitory interactions arising from feedforward and feedback interactions to, and lateral interactions within, V1 (Gilbert and Wiesel, 1990; Jones et al., 2000; Angelucci et al., 2002; Bair et al., 2003; Angelucci and Bressloff, 2006; Solomon et al., 2006; Alitto

Received April 10, 2015; revised July 28, 2015; accepted July 29, 2015.

Author contributions: A.V.F. and S.O.M. designed research;A.V.F. performed research; A.V.F. and S.O.M. analyzed data; A.V.F. and S.O.M. wrote the paper.

This research was supported by a National Science Foundation CAREER award to S.0.M. (0845901) and a National Eye Institute Training Grant to A.V.F. (EY07031). We thank Geoffrey M. Boynton for providing the MATLAB functions for the model implementation (supported by EY12925).

The authors declare no competing financial interests.

Correspondence should be addressed to Anastasia V. Flevaris, Department of Psychology, University of Washington, Seattle, WA 98195. E-mail: ani.flevaris@gmail.com.

DOI:10.1523/JNEUROSCI.1409-15.2015

Copyright $\odot 2015$ the authors $\quad 0270-6474 / 15 / 3512273-08 \$ 15.00 / 0$ and Usrey, 2008; Adesnik et al., 2012; Nassi et al., 2013; Nurminen and Angelucci, 2014).

In direct contradiction to suppression, responses in V1 to an oriented stimulus can also be enhanced when flanked by isooriented stimuli compared with orthogonally oriented stimuli. This orientation-tuned surround enhancement is believed to be caused by an automatic spread of attention (Ito and Gilbert, 1999; Li et al., 2006; Wannig et al., 2011). Attentional enhancement has been shown to automatically spread to items in an image that are perceptually grouped with an attended stimulus (Roelfsema et al., 1998; Marcus and Van Essen, 2002; Serences et al., 2004; Martinez et al., 2007; Qiu et al., 2007; Wannig et al., 2011; Flevaris et al., 2013) and/or share features with an attended stimulus (Shih and Sperling, 1996; Beauchamp et al., 1997; O'Craven et al., 1997; Treue and Martinez Trujillo, 1999; McAdams and Maunsell, 2000; Saenz et al., 2002; 2003; Martinez-Trujillo and Treue, 2004; Maunsell and Treue, 2006; Schoenfeld et al., 2007; Zhang and Luck, 2009). To account for these seemingly contradictory findings, we speculated that orientation-tuned suppression versus enhancement depends on the relationship between the stimulus configuration and which element in an array is attended, a prediction that emerges from a model that incorporates feature-based attentional enhancement and re- 
sponse normalization (Reynolds and Heeger, 2009). Specifically, we predicted that attending to a center stimulus would yield orientation-tuned surround suppression, whereas attending to a flanker would yield orientation-tuned surround enhancement due to feature-based attention spreading to the similarly oriented center stimulus.

\section{Materials and Methods}

fMRI experiment. We presented three-element arrays of Gabors-a center Gabor with two flanking Gabors, with an array in each visual field - and used fMRI to assess how directing attention to different elements in the array modulates the response in V1 to the center Gabor (Fig. 1). While maintaining central fixation, subjects were cued to one of the Gabors for the entirety of an fMRI scan-either one of the center (left or right) or one of the upper (left or right) Gabors. Participants performed a contrast increment/decrement task on the attended Gabor while ignoring contrast changes at all other locations.

Participants. Sixteen students (10 women) from the University of Washington (ages 1931) participated in the experiment. All gave written informed consent as approved by the University of Washington Institutional Review Board. Four participants were excluded from the analyses due to excessive head motion in the scanner $(>1 \mathrm{~mm}$ on successive image acquisitions in all of the runs of any experimental condition). One additional participant was excluded due to an inability to isolate the center location in V1 in both hemispheres, leaving a total of 11 participants (seven women).

Stimuli and experimental procedure. Described similarly in Flevaris and Murray (2014), participants maintained fixation on a central black fixation cross that subtended $0.4^{\circ}$ and remained on the screen throughout the experiment. Six small black circles subtending $0.3^{\circ}$ surrounded the fixation cross. The two center circles were located $0.2^{\circ}$ to the left and right of the cross; the remaining circles were $0.2^{\circ}$ above and below the center circle on each side. These small black circles signified the location of six Gabor patches that were presented $3.8^{\circ}$ to the left and right of the fixation cross, three on each side. The center-to-center distance of each center Gabor to the upper and lower flanking Gabors was 3.8 ${ }^{\circ}$. The Gabor patches were generated using the MATLAB Psychtoolbox (Brainard, 1997), and had a spatial frequency of 2 cycles/degree, $75 \%$ contrast, and were Gaussian windowed with $0.7^{\circ} \mathrm{SD}$. Both center and flanking Gabors shifted in phase together every $500 \mathrm{~ms}$ to prevent adaptation effects. The center Gabors were kept at a fixed orientation, while the flanking Gabor orientation varied, to compare the BOLD response to physically identical stimuli. The center Gabors had vertical orientation and the flanking Gabors had either vertical or horizontal orientation, yielding iso-oriented and orthogonal conditions, respectively. In previous fMRI, ERP, and psychophysical experiments using such three-element arrays and varying the center Gabor orientation, we found similar differences between isooriented and orthogonal stimulus conditions independent of the absoexample).
Iso-oriented "attend upper left"

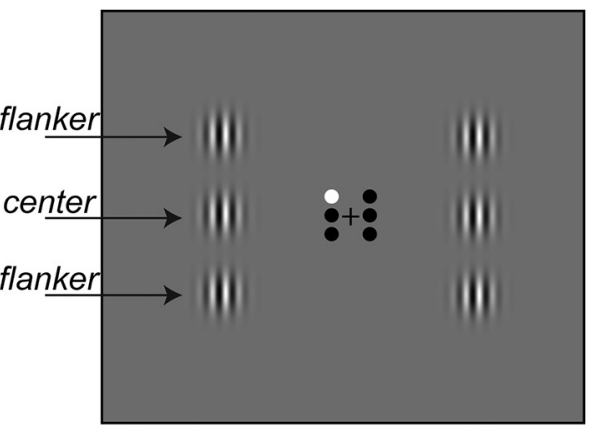

Figure 1. Example of the stimulus configurations used in the fMRI experiment. Identical three-element arrays of Gabors appeared in each visual field and participants attended to one Gabor in one visual field for an entire fMRI scan (see text). Participants were cued to the location of the Gabor to be attended in the scan by one of the circles surrounding the fixation cross appearing white (i.e., indicating to attend to the upper left Gabor in the left example and to attend to the center left Gabor in the right a

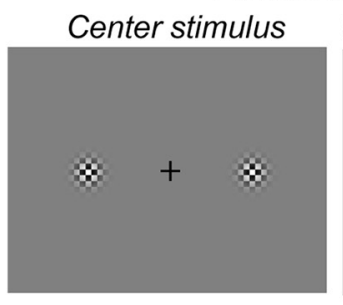

C

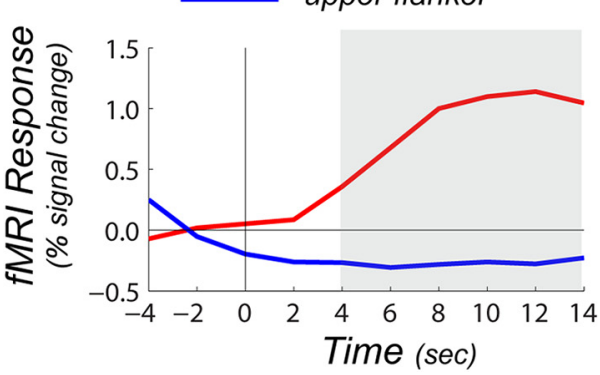

b

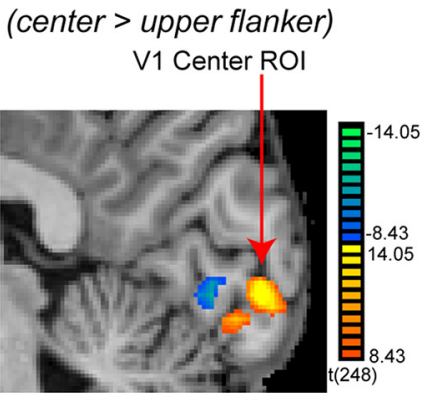

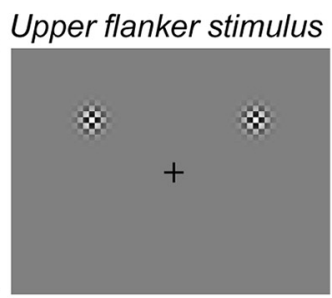

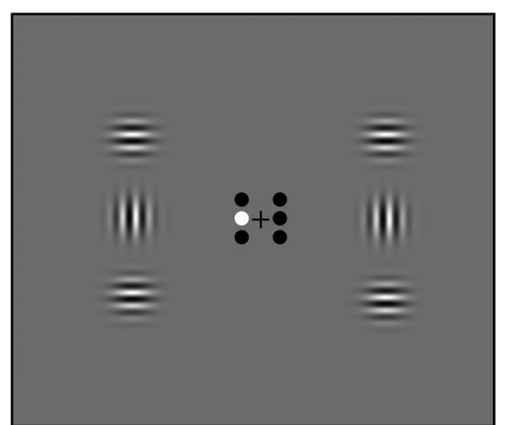

Figure 2. ROl definition. $\boldsymbol{a}$, Depictions of the stimuli positioned in the center location (left) and upper flanker location (right). $\boldsymbol{b}$, An example from a single subject of a statistical contrast between the two stimulus types with the arrow pointing to a contiguous region within the calcarine sulcus used to define V1. c, The average time course across subjects from the center R0I in response to the center stimulus (red) and upper flanker stimulus (blue). Gray region indicates time points that were averaged to produce the average response in the center ROI to the two localizer stimuli $(\boldsymbol{d})$. Error bars indicate SEM.

lute orientation of the elements (but see Essock et al., 2009; Kim et al., 2010; Joo et al., 2012; Joo and Murray, 2014).

Trial timing was controlled by Presentation (Neurobehavioral Systems). Participants were instructed to attend to one Gabor in each stimulus scan and look for contrast changes at the attended location, indicating via button press if the contrast increased or decreased when such a change occurred. During each scan one of the six small circles was colored white to signify the location of the Gabor that was to be attended during that scan. Contrast changes occurred twice on each Gabor during each $12 \mathrm{~s}$ block, yielding 12 total contrast changes per block. Contrast changes occurred in random order across the attended and unattended Gabors. A contrast change consisted of either a decrease from 75 to $50 \%$, or an increase to $100 \%$. For a given contrast change, whether the contrast 


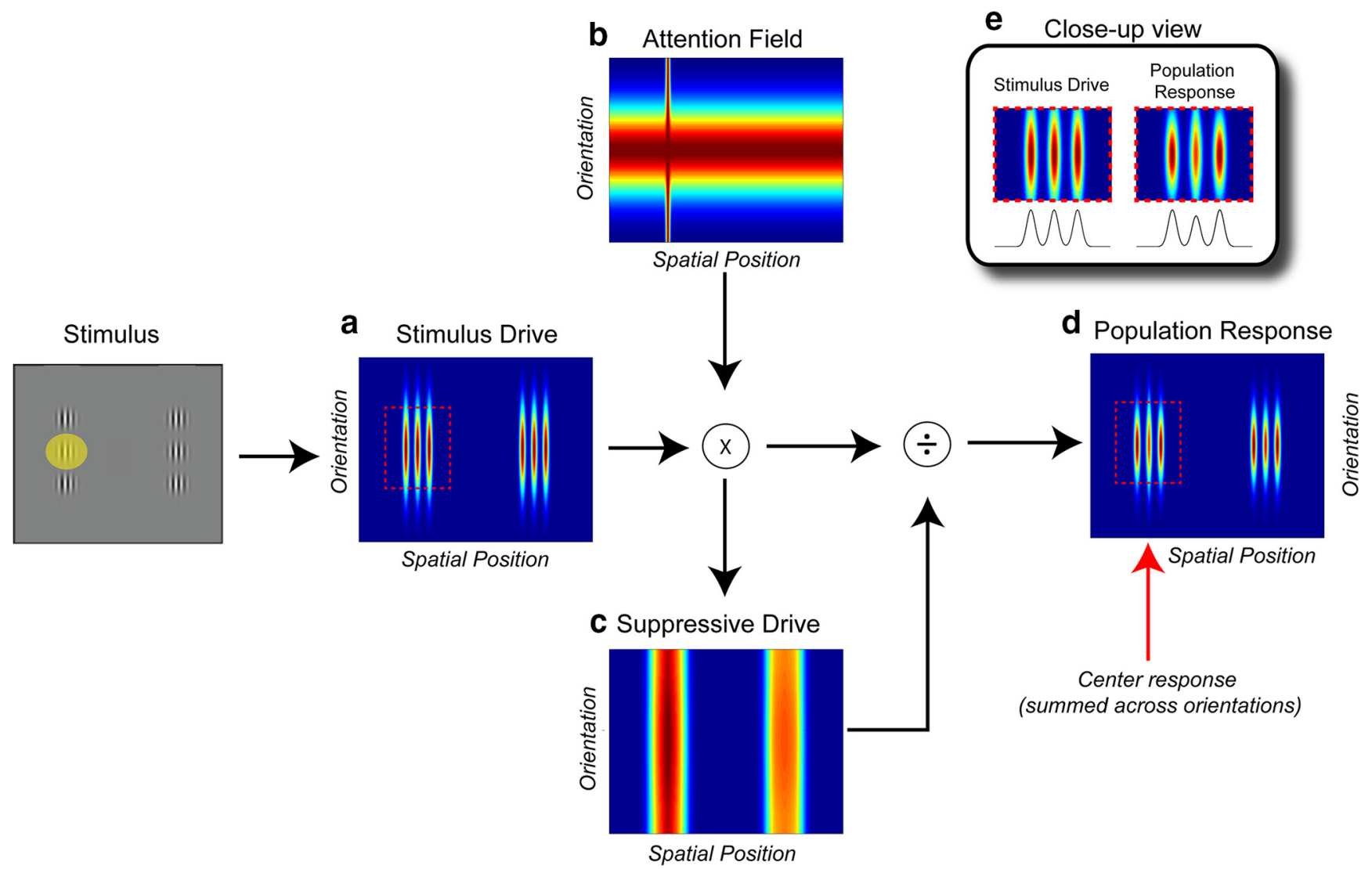

Figure 3. Model components. One of the stimulus arrangements used in the experiment is shown on the left. When attention is directed to the left center Gabor (represented by the yellow circle), the stimulus produces the Stimulus Drive for a collection of neurons with different receptive field positions and orientation tuning $(\boldsymbol{a})$. Red indicates large values and blue represents zero. $\boldsymbol{b}$, The Attention Field when attention is directed to the center Gabor. The thin vertical line represents spatial attention and the wide horizontal line represents feature-based attention. The Attention Field is multiplied by the Stimulus Drive. The Suppressive Drive (c) is computed from the product of the Stimulus Drive and the Attention Field. The Population Response (d) is computed by dividing the Stimulus Drive by the Suppressive Drive. $\boldsymbol{e}$, Close-up views of the Stimulus Drive and Population Response with a cross section of the relative amplitude of the responses to the three stimuli.

\section{Table 1. Model parameters}

\begin{tabular}{|c|c|c|c|c|c|c|c|}
\hline \multicolumn{2}{|c|}{ Stimulus } & \multirow{2}{*}{\multicolumn{2}{|c|}{ Stimulus field }} & \multirow{2}{*}{\multicolumn{2}{|c|}{ Suppressive field }} & \multirow{2}{*}{\multicolumn{2}{|c|}{ Attention field }} \\
\hline \multirow[b]{2}{*}{ Size } & \multirow{2}{*}{$\begin{array}{l}\text { Interstimulus } \\
\text { distance }\end{array}$} & & & & & & \\
\hline & & RF size & Tuning & RF size & Tuning & Width & Tuning \\
\hline 5 & 40 & 5 & $30^{\circ}$ & 20 & $180^{\circ}$ & 5 & $30^{\circ}$ \\
\hline
\end{tabular}

The values are used in the model simulations. Spatial sizes are in arbitrary units; only the relative sizes are meaningful. Tuning is in degrees corresponding to the SD of a Gaussian. RF, receptive field.

increased or decreased was random. The task was designed to direct attention to the cued stimulus and to have the same level of difficulty across iso-oriented and orthogonal conditions. Participants attended the center left, center right, upper left, and upper right locations in separate scans in counterbalanced order, and each location was attended twice in an experimental session. Hence, each participant was run on eight stimulus scans. The order of conditions was counterbalanced across participants. A stimulus scan (300 s) consisted of three stimulus conditions presented in alternating $12 \mathrm{~s}$ blocks: (1) fixation (F), (2) stimulus block with center and flanking Gabors at the same orientation (S), and (3) stimulus block with center and flanking Gabors at an orthogonal orientation $(\mathrm{O})$. The fixation condition was inserted between each stimulus condition and the scan began and ended with the fixation condition (F-S-F-O-F...F).

Participants were also run on two localizer scans in which Gaussianwindowed checkerboards $\left(0.7^{\circ} \mathrm{SD}\right)$ counterphase flickered at $10 \mathrm{~Hz}$, either in the location of the center Gabor in each visual field or at the location of the upper flankers in each visual field (Fig. 2a). A localizer scan (252 s) consisted of three stimulus conditions presented in alternat- ing 12 s blocks: (1) fixation (F), (2) stimulus block with checkerboards at the location of the center Gabors (C), and (3) stimulus block with checkerboards at the location of the flanking Gabors (F). The fixation condition was inserted between each stimulus condition and the scan began and ended with the fixation condition (F-C-F-U-F...F).

fMRI acquisition and analysis. fMRI data were acquired using a Philips Achieva $3 \mathrm{~T}$ scanner using a 32-channel head coil and an echo-planar imaging sequence (repetition time, $2 \mathrm{~s}$; flip angle, $70^{\circ}$; 30 axial slices of 3 $\mathrm{mm}$ thickness $(0.5 \mathrm{~mm}$ gap) and $3.0 \times 3.0 \mathrm{~mm}$ in-plane resolution; field of view, $240 \mathrm{~mm}$ ). Each scanning session began with a T1-weighted structural scan with $1 \times 1 \times 1 \mathrm{~mm}$ resolution used for visualization of retinotopic visual areas. Visual cortical area V1 was localized using standard retinotopic mapping techniques using BrainVoyager QX. ROIs in the left and right primary visual cortex (V1) were defined using the localizer scan. We performed a statistical contrast between the center and flanker stimulus conditions, Bonferroni corrected based on the total number of voxels $\left(p=10^{-3}\right)$. Next, we identified the largest contiguous region of statistical significance within the calcarine sulcus (Fig. $2 b$ ). From that contiguous region we then selected the 20 voxels with the highest statistical values, a procedure that ensured that each subject had the same ROI size. The center ROI was highly selective as assessed by examining its response in the localizer scans - it only had a significantly higher response from fixation baseline in response to the localizer stimulus in the center location and not in the flanker location (Fig. $2 c, d$ ). Because the center stimulus was located along the horizontal meridian it was not possible to differentiate V2 and V3. However, we used the same procedures described above for defining a combined "V2/V3" ROI (the ventral V2/V3 ROI is partially visible beneath the V1 ROI in Fig. 2b).

Time courses for each of the stimulus scans were extracted and averaged across voxels within each ROI. The signal intensity in each condi- 
tion was time locked to the onset of the stimuli and averaged, from $2 \mathrm{~s}$ before the onset to $14 \mathrm{~s}$ after the onset. The $2 \mathrm{~s}$ before stimulus onset served as a baseline, and the percentage signal change relative to the baseline was calculated and used as the measure of mean percentage signal change in each condition. Mean percentage signal change between 4 and $14 \mathrm{~s}$ after stimulus onset was averaged and entered into statistical analyses.

Normalization model. Our implementation of the normalization model of attention closely follows Reynolds and Heeger (2009). The model was implemented using custom MATLAB functions written by G. M. Boynton. The model is a qualitative characterization of idealized responses of a population of neurons in visual cortex. The model is implemented using "neural images" that represent the response of a population of neurons selective for featural dimensions which, here, include spatial position and orientation (Fig. 3). For convenience, spatial position is represented as a single onedimensional vector which, without any loss of generality, can be thought of as twodimensional space unwrapped into a single vector. The model has four components: (1) Stimulus Drive, which represents the excitatory response of the population in the absence of attention or suppressive influences; (2) Attention Field, which includes response gain for all neurons selective for a specific position ("spatial attention") and specific orientation ("feature-based attention"); (3) Suppressive Drive, which represents a normalization factor based on the pooled response across a wide range of orientations (Heeger, 1992; Reynolds and Heeger, 2009); and (4) Population Response, which is the final population response obtained by multiplying the Stimulus Drive by the Attention Field and then normalizing by the Suppressive Drive. Similar to previous implementations of the model, a given neuron's stimulus-driven excitatory response (Fig. $3 a$ ) is inhibited divisively by neurons tuned to all orientations (Fig. 3c). The key element of our implementation is a "feature enhancement" component in the Attention Field (Fig. 3b)—attention to a stimulus at one location leads to an enhanced response to all other stimuli in the visual field that share the attended orientation (Herrmann et al., 2012). To approximate the fMRI response magnitude in an ROI sensitive to spatial position (retinotopy) but insensitive to orientation, we summed the values of the population response across all orientations at the spatial position of the center Gabor. The summed value was then normalized to 1.0. Specific parameters of the model are shown in Table 1.

\section{Results}

Behavioral results

As expected, performance did not differ between iso-oriented and orthogonal flanker orientations. Though contrast-increment thresholds and perceived contrast have been shown to be dependent on surround configurations (Snowden and Hammett, 1998; Xing and Heeger, 2000; Zenger-Landolt and Heeger, 2003; Joo et al., 2012; Joo and Murray, 2014; Flevaris and Murray, 2015), our task was well above threshold and was simply meant to direct attention to the cued stimulus. Neither response time (RT) nor $d^{\prime}$ in reporting contrast changes at the attended location differed between iso-oriented and orthogonal conditions $\left(F_{(1,10)}<1\right.$ and $F_{(1,10)}<1$ for RT and $d^{\prime}$, respectively), nor did attention interact with flanker orientation for either behavioral measure $\left(F_{(1,10)}=\right.$ $3.7, p=\mathrm{ns}$, and $F_{(1,10)}=3.3, p=\mathrm{ns}$ for $\mathrm{RT}$ and $d^{\prime}$, respectively). The absence of an effect of flanker orientation and of attention on flanker orientation may have been due to a ceiling effect on performance, because the task was well above threshold. For both RT b

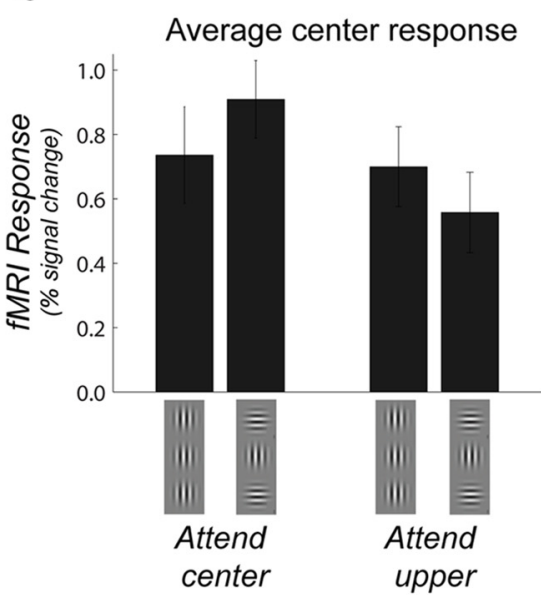

and $d^{\prime}$, task performance was facilitated when attention was directed to a central Gabor (775 ms and 4.5 for RT and $d^{\prime}$, respectively) relative to an upper flanker ( $853 \mathrm{~ms}$ and 2.8 for RT and $d^{\prime}$, respectively; $F_{(1,10)}=33.8, p=0.0002$ and $F_{(1,10)}=8.04, p=0.02$ for RT and $d^{\prime}$, respectively).

\section{fMRI results}

Mean percentage signal change in the region of $\mathrm{V} 1$ responding to the center Gabor was analyzed with a $2 \times 2$ repeated-measures ANOVA with attended location (center, upper) and flanker orientation (iso-oriented, orthogonal) as factors. Consistent with an abundance of literature on spatial attention (Gandhi et al., 1999; Martínez et al., 1999; Murray, 2008), we observed a main effect of attended location $\left(F_{(1,10)}=14.8, p=0.003\right)$, indicating a larger response when attention was directed to the center versus the upper flanking stimulus. More importantly, the effect of flanker orientation on the center response depended on the spatial focus of attention (Fig. 4), evidenced by a significant interaction between attended location and flanker orientation $\left(F_{(1,10)}=16.7\right.$, $p=0.002)$. Specifically, we observed orientation-tuned surround suppression when attention was directed to the center Gabor: responses to the center Gabor were reduced with iso-oriented (0.74) versus orthogonal (0.91) flankers (Fig. $4 ; t_{(10)}=-2.64$, $p=0.02)$. However, when attention was directed to the upper flanker, we observed orientation-tuned surround enhancement: responses to the center Gabor were greater with iso-oriented $(0.70)$ versus orthogonal $(0.56)$ flankers $\left(t_{(10)}=2.68, p=0.02\right)$. Overall, these results demonstrate that the sign of contextual effects in V1-enhancement versus suppression-depends on the focus of attention; shifting attention by one element in the array can switch the contextual effect from suppression to enhancement.

\section{Model results}

We were able to explain the interaction between attention and flanker orientation using the normalization model of attention (Fig. 5; Reynolds and Heeger, 2009). The population response of 
a

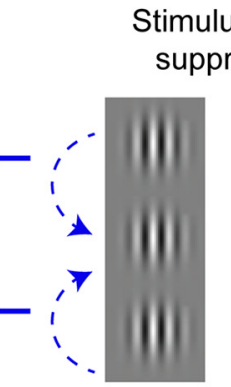
sulus-based uppression

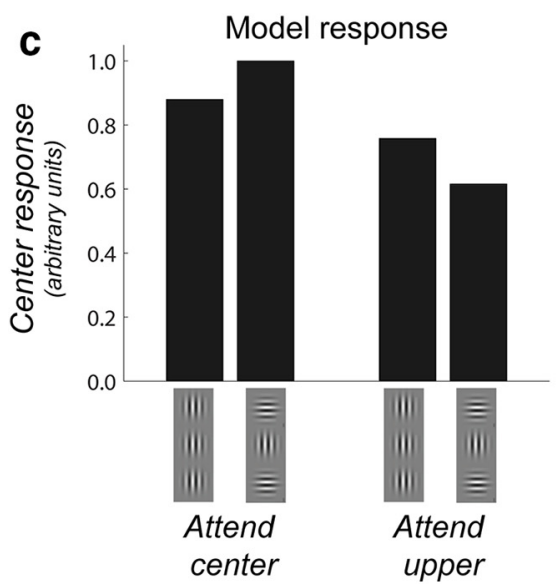

\section{b enhancement}

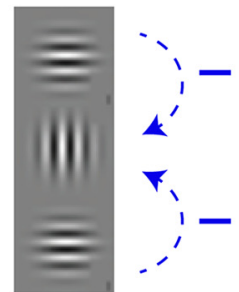

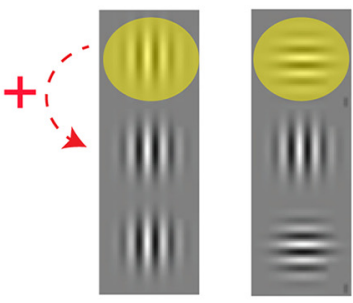

\section{d}

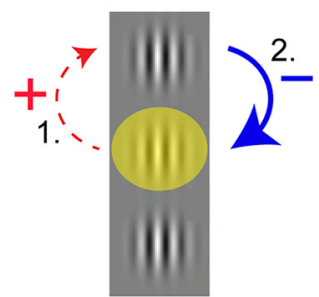

Figure 5. Model depiction and results. $\boldsymbol{a}$, Effect of divisive normalization: surrounding stimuli of all orientations inhibit the center Gabor to an equivalent degree. $\boldsymbol{b}$, Effect of feature-based attention: attention to a Gabor of a particular orientation (represented by yellow circle) enhances the response to similarly oriented Gabors. Hence, attention to an iso-oriented flanker enhances the response to the center Gabor whereas attention to an orthogonal flanker does not. c, Response of the model to the center Gabor shown separately for iso-oriented versus orthogonal flanker orientation when attention was directed to the center Gabor itself and when attention was directed to the upper flanker. $\boldsymbol{d}$, Emergence of orientation-tuned suppression results from a combination of $\boldsymbol{a}$ and $\boldsymbol{b}$. When attention is directed to the center Gabor, attention-based enhancement increases the response to the upper flanker when it is iso-oriented (1, red arrow) but not when it is orthogonal. This in turn causes greater suppression of the center Gabor by the flanker (2, blue arrow).

a

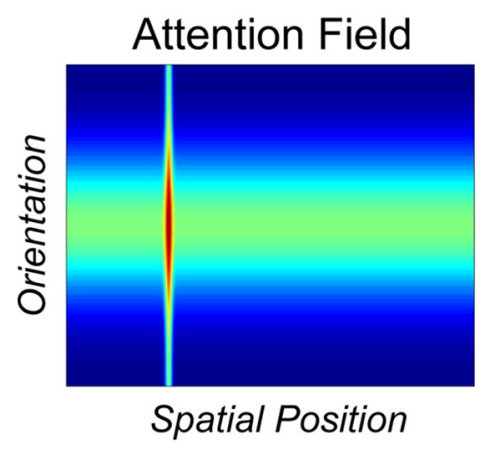

b

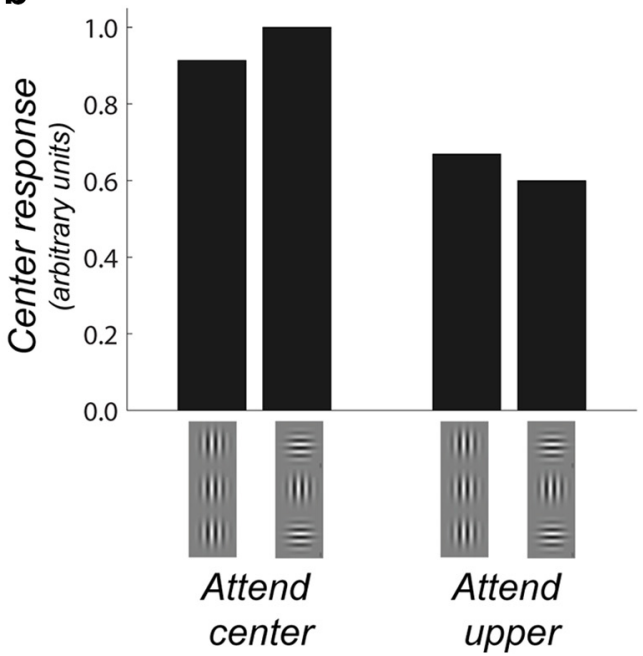

Figure 6. Model alternative. $\boldsymbol{a}$, An alternative way of combining spatial-based and feature-based attention in the Attention Field produces qualitatively similar results $(\boldsymbol{b})$.

the model to the center Gabor is represented by the summed values across orientation at the spatial position of the center Gabor in Figure $3 d$. Figure 5, $a$ and $b$, shows a schematic depiction of the two key features of the model and how the center Gabor and

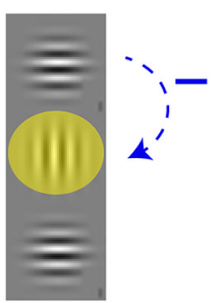

flankers interact in the experiment: suppression occurs from flankers of all orientations under all attention conditions (Fig. 5a) and feature-based attention selectively enhances the response to the center Gabor when attention is directed to a flanker of matching orientation. The results of the model are qualitatively similar (Fig. $5 c$ ) to our observed fMRI findings (Fig. 4b).

The model provides a simple explanation for how orientation-tuned surround suppression can emerge despite having no orientation tuning in the normalization term. First, when attention is directed to the center element feature-based enhancement increases the response to the flankers when they are iso-oriented but not when they are orthogonal. This overall enhanced response to the iso-oriented flankers, in turn, leads to greater suppression of the center Gabor by the flankers (Fig. 5d). The model also accounts for orientation-tuned surround enhancement when attention is directed to a flanker: inhibition of the center Gabor by the flankers is equivalent with iso-oriented and orthogonal flankers, but there is an additional feature-based attentional enhancement with iso-oriented flankers that spreads to the center Gabor (Fig. 5b).

The pattern of results of the model holds across a wide range of realistic parameter values. We assumed that the width of the spatial component of the Attention Field (Fig. 3b, narrow vertical stripe) was the same as the width of the stimulus, as if subjects' attentional window was restricted to the stimulus being attended. However, large changes of this parameter do not alter the pattern of results of the model. We also assumed that the width of the feature-based component of the attention field (Fig. $3 b$, horizontal stripe) was the same as the width of the orientation tuning width of the neurons in the model (30 degrees); that is, attention would increase gain in a manner equivalent to the orientation tuning of the neurons. The basic pattern of results holds up to a tuning width approximately three times the orientation tuning width of the model neurons, and thus is robust across a wide range of realistic values. The model is also robust across large changes in receptive field (RF) size of the model neurons; the same predictions hold up to RF sizes four times the size used in the simulations. The spatial-based and feature-based components are invariant across features and space, respectively, even where the effects are overlapping. However, other forms of combining the spatial-based and feature-based components of the model produce similar results. For example, Figure 6 shows an 
a

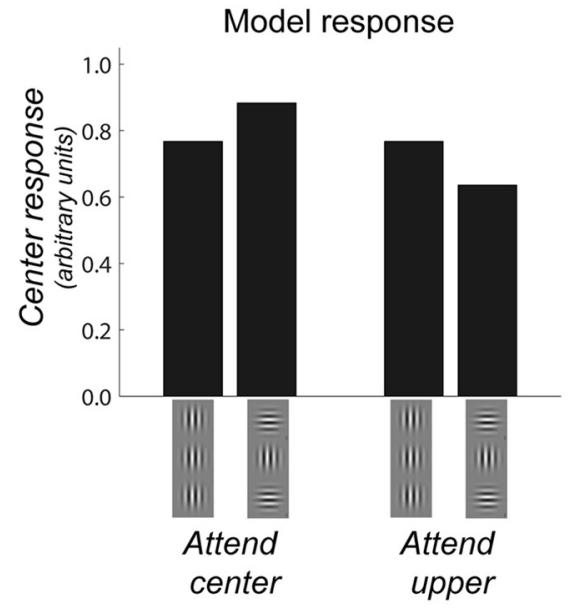

b

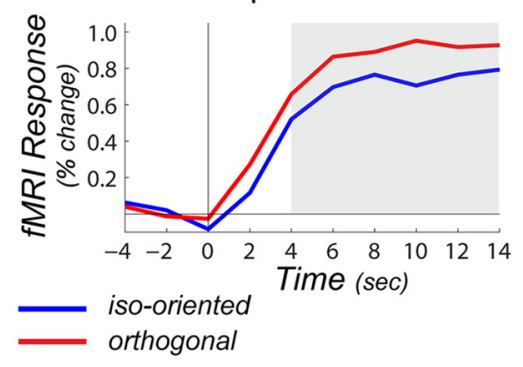

Center response: attend upper

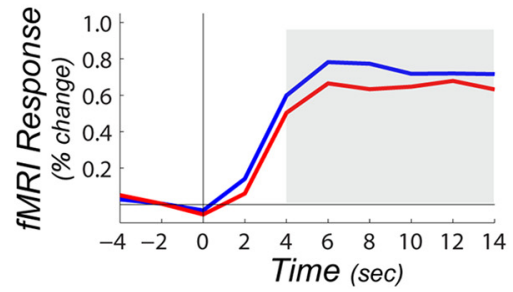

C

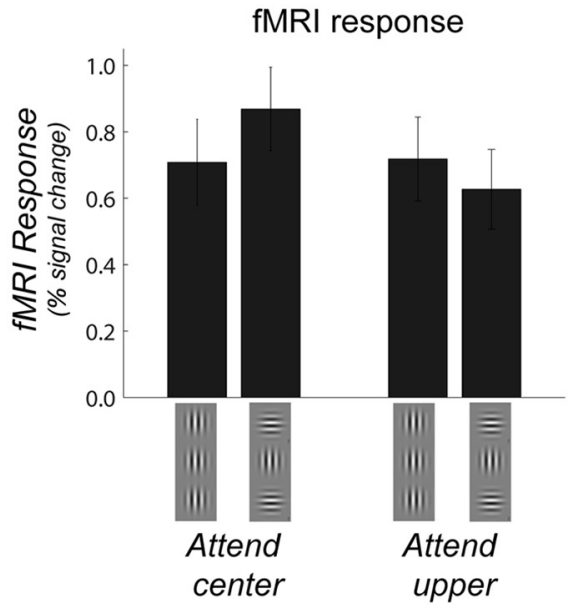

Figure 7. Model and fMRI results for the ipsilateral hemisphere. $\boldsymbol{a}$, Response of the model to the ipsilateral (unattended) center Gabor shown separately for iso-oriented versus orthogonal flankers when attention was directed to the contralateral center Gabor versus when attention was directed to the contralateral upper flanker. $\boldsymbol{b}$, Average time course of the fMRI response to the ipsilateral center Gabor shown separately for iso-oriented versus orthogonal flanker orientation when attention was directed to the contralateral center Gabor (top) and when attention was directed to the contralateral upper flanker (bottom). $\boldsymbol{c}$, Average ipsilateral fMRI response between 4 and $14 \mathrm{~s}$ after stimulus onset (shaded region in $\boldsymbol{b}$ ), shown separately for each condition. Error bars indicate SEM.

Attention Field where the two spatial and feature components were combined so that there is increased gain where the two components overlap (Fig. $6 a$, bright red in the Attention Field). Finally, the effect was robust to changes in the spatial tuning of the Suppressive Drive, as long as the width was large enough to incorporate the flanking stimuli.

\section{Ipsilateral hemisphere results}

To investigate the extent of feature-based enhancement, we also examined the model's responses to the center element in the hemisphere ipsilateral to the direction of attention (e.g., the response in the left hemisphere V1 when attention was directed to the left visual field). In our experiment, we presented identical displays in each visual field, but spatial attention was directed to a center Gabor or flanker in only one visual field, represented by the contralateral hemisphere. Hence, the ipsilateral hemisphere represents spatially unattended stimuli that are otherwise identical to the attended stimuli. The model predicts a similar pattern of results for the ipsilateral hemisphere (Fig. 7a): suppression when attention is directed to the center element in the opposite visual field and enhancement when attention is directed to a flanker. That is, when attention is directed to a center Gabor in one visual field, feature enhancement increases the response to the flankers in the opposite visual field when they are iso-oriented but not when they are orthogonal, which in turn leads to greater suppression of the center Gabor in the unattended visual field by its flankers. In contrast, when attention is directed to a flanker, feature enhancement increases the response to the center Gabor and flankers in the opposite visual field when they are isooriented, but only to the flankers when they are orthogonal, leading to an overall greater response to the unattended center Gabor in the iso-oriented relative to the orthogonal condition. The only notable difference in the model results for the ipsilateral hemisphere is an absence of a spatial attention effect (i.e., no difference in the response to the center Gabor when the center Gabor-in the opposite visual field - is attended relative to when a flanker is attended), which is expected because neither the center Gabor nor the flankers were attended.

Consistent with the model, we observed a qualitatively similar pattern of results in our ipsilateral fMRI data (Fig. $7 b, c$ ). Mean percentage signal change in the region of V1 responding to the ipsilateral center Gabor (i.e., the center element opposite the side of spatial attention) was analyzed with a $2 \times 2$ repeated-measures ANOVA with attended location in the opposite hemifield (central, upper) and flanker orientation (iso-oriented, orthogonal) as factors. This analysis revealed a significant attended location $X$ orientation interaction $\left(F_{(1,10)}=10.2, p=0.01\right)$. Follow-up $t$ tests revealed trends demonstrating a similar pattern of results as found for the contralateral hemisphere. When participants attended to the center Gabor in the opposite visual field, responses in the ipsilateral hemisphere to the (unattended) center Gabor were reduced in the iso-oriented (0.71) relative to the orthogonal $(0.87)$ condition $\left(t_{(10)}=-2.46, p=0.03\right)$, and when participants attended to the upper flanker, responses in the ipsilateral hemisphere to the center Gabor were enhanced in the iso-oriented (0.72) relative to the orthogonal $(0.63)$ condition, $\left(t_{(10)}=2.02, p=0.07\right)$.

\section{Extrastriate results}

We performed the same analysis in a combined "V2/V3" ROI with results that mimicked the findings in V1. Specifically, in both the contralateral (significant) and ipsilateral (trend) ROIs, we observed a main effect of attended location (Contra: $F_{(1,10)}=$ 26.9, $p=0.0004$; Ipsi: $\left.F_{(1,10)}=4.85, p=0.052\right)$. More importantly, we observed the same significant interaction between attended location and flanker orientation (Contra: $F_{(1,10)}=13$, $p=0.0048$; Ipsi: $\left.F_{(1,10)}=13.2, p=0.004\right)$. Planned comparisons revealed the same pattern of results as $\mathrm{V} 1$; orientation-tuned surround suppression when attention was directed to the center Gabor: iso-oriented (0.75 Contra; $0.68 \mathrm{Ipsi}$ ) versus orthogonal (0.92 Contra; 0.82 Ipsi) flankers (Contra: $t_{(10)}=-2.69, p=0.02$; Ipsi: $\left.t_{(10)}=-2.77, p=0.02\right)$. However, when attention was directed to the upper flanker, we observed orientation-tuned sur- 
round enhancement: responses to the center Gabor were greater with iso-oriented ( 0.70 Contra; $0.69 \mathrm{Ipsi}$ ) versus orthogonal ( 0.55 Contra; 0.59 Ipsi) flankers (Contra: $t_{(10)}=3.71, p=0.004$ ); Ipsi: $\left.t_{(10)}=2.6, p=0.03\right)$. The results from $\mathrm{V} 2 / \mathrm{V} 3$, which have larger RFs than V1, are also consistent with the model; the model predictions hold across a wide range of RF sizes.

\section{Discussion}

We have shown that shifting attention by a single element can switch stimulus-based contextual effects from suppression to enhancement. This seemingly complex interaction between flanker orientation (iso-oriented vs orthogonal) and attention (to the center Gabor vs flanker) can be accounted for by including feature-based attentional enhancement within the normalization model of attention and does not require orientation tuning of the suppression. The extent to which inhibitory influences are orientation tuned is unclear: orientation tuning appears to be required to explain some contextual effects (Blakemore and Tobin, 1972; Gilbert and Wiesel, 1990; Shushruth et al., 2013), but is not always required to explain suppressive phenomena. For example, suppression of responses to an optimally oriented stimulus by a superimposed orthogonal stimulus ("cross-orientation suppression") appears to require no orientation tuning of the suppression (Bonds, 1989; DeAngelis et al., 1992). Our implementation of the normalization model demonstrates that orientation-tuned surround suppression can emerge despite no orientation tuning in the normalization term by incorporating effects of attentional enhancement. That is, feature-based attentional spreading modulates the strength of the flankers, which in turn determines the amount of suppression of the center Gabor. The model provides a potentially more parsimonious account for orientation-tuned suppression than, for example, similar models that must first specifically evaluate the statistical relationship between the center and surround (Schwartz and Coen-Cagli, 2013). However, as electrophysiological results in animals under anesthesia have shown (Blakemore and Tobin, 1972; DeAngelis et al., 1994; Li and Li, 1994; Sillito et al., 1995; Walker et al., 1999; Cavanaugh et al., 2002; Shushruth et al., 2012), attention is not necessary for orientation-tuned suppression to occur. Hence, there may be both attention-dependent and attention-independent forms of orientation-tuned suppression. To examine this issue more carefully, we implemented our model with various orientation tuning widths in the suppressive field. The same pattern of model predictions holds as long as the suppressive drive has fairly broad orientation tuning, up to approximately three times the tuning width of the excitatory RF tuning. As the suppressive field becomes very narrowly tuned the attentional-enhancement effect (Fig. $5 b$ ) is counteracted and eventually eliminated. It should be noted that normalization is generally considered to be broadly orientation tuned (Heeger, 1992; Reynolds and Heeger, 2009). Thus there is a considerable regime under which both attentiondependent and attention-independent forms of orientationtuned suppression could operate.

The feature enhancement component of the model is akin to the concept of global feature-based attention: when a specific feature (e.g., color, orientation, motion direction) is attended at one location, there is response enhancement to matching features at all other locations (Shih and Sperling, 1996; Beauchamp et al., 1997; O'Craven et al., 1997; Treue and Martinez Trujillo, 1999; McAdams and Maunsell, 2000; Saenz et al., 2002; 2003; Martinez-Trujillo and Treue, 2004; Maunsell and Treue, 2006; Schoenfeld et al., 2007; Zhang and Luck, 2009). Strictly speaking, our experiment did not measure feature-based attention, because the fMRI effects that we measured were orientation specific and the subjects' task was to discriminate luminance contrast. However, since orientation is a defining feature of a Gabor, it is likely that attending to any aspect of a Gabor automatically incorporates orientation. For example, studies have shown that attending to one part of an object or group automatically enhances processing of all elements of the object/group (Roelfsema et al., 1998; Marcus and Van Essen, 2002; Serences et al., 2004; Martinez et al., 2007; Qiu et al., 2007; Wannig et al., 2011; Flevaris et al., 2013).

One limitation of our design was that the center Gabor was always vertically oriented - only the flanker orientation changed between conditions. Thus an open question is whether our results generalize to other stimulus configurations, as in previous fMRI, ERP, and psychophysical studies that have observed equivalent orientation-dependent effects for both vertically and horizontally orientated center stimuli (but see, Essock et al., 2009; Kim et al., 2010; Joo et al., 2012; Joo and Murray, 2014). Also, because the stimuli at the flanker locations were physically different between iso-oriented and orthogonal conditions and there may be intrinsic orientation preferences (either at the neural or voxel level), we were unable to meaningfully analyze the response in an ROI selective for the upper flanker location. However, the normalization model makes testable predictions of the flanker response that could be examined in future experiments designed to specifically investigate the flanker response.

One simplifying assumption of the normalization model is that feature-based enhancement is invariant across space. While there is some evidence that this may be true (Rossi and Paradiso, 1995; Saenz et al., 2002; Martinez-Trujillo and Treue, 2004; Maunsell and Treue, 2006), it is likely that grouping-based mechanisms also contributed to our results. Indeed, recent evidence suggests that mechanisms underlying the attention to features, objects/ groups, and space can interact (Müller and Kleinschmidt, 2003; Kravitz and Behrmann, 2008, 2011). We might thus expect featurebased enhancement to vary across space and be greater for the object/group/contour attended. Future research is necessary to more specifically isolate these attentional components.

\section{References}

Adesnik H, Bruns W, Taniguchi H, Huang ZJ, Scanziani M (2012) A neural circuit for spatial summation in visual cortex. Nature 490:226-231. CrossRef Medline

Alitto HJ, Usrey WM (2008) Origin and dynamics of extraclassical suppression in the lateral geniculate nucleus of the macaque monkey. Neuron 57:135-146. CrossRef Medline

Angelucci A, Bressloff PC (2006) Contribution of feedforward, lateral and feedback connections to the classical receptive field center and extraclassical receptive field surround of primate V1 neurons. Prog Brain Res 154:93-120. CrossRef Medline

Angelucci A, Levitt JB, Walton EJ, Hupe JM, Bullier J, Lund JS (2002) Circuits for local and global signal integration in primary visual cortex. J Neurosci 22:8633-8646. Medline

Bair W, Cavanaugh JR, Movshon JA (2003) Time course and time-distance relationships for surround suppression in macaque V1 neurons. J Neurosci 23:7690-7701. Medline

Beauchamp MS, Cox RW, DeYoe EA (1997) Graded effects of spatial and featural attention on human area MT and associated motion processing areas. J Neurophysiol 78:516-520. Medline

Blakemore C, Tobin EA (1972) Lateral inhibition between orientation detectors in the cat's visual cortex. Exp Brain Res 15:439-440. CrossRef Medline

Bonds AB (1989) Role of inhibition in the specification of orientation selectivity of cells in the cat striate cortex. Vis Neurosci 2:41-55. CrossRef Medline

Brainard DH (1997) The Psychophysics Toolbox. Spat Vis 10:433-436. CrossRef Medline

Cavanaugh JR, Bair W, Movshon JA (2002) Nature and interaction of signals from the receptive field center and surround in macaque V1 neurons. J Neurophysiol 88:2530-2546. CrossRef Medline 
DeAngelis GC, Robson JG, Ohzawa I, Freeman RD (1992) Organization of suppression in receptive fields of neurons in cat visual cortex. J Neurophysiol 68:144-163. Medline

DeAngelis GC, Freeman RD, Ohzawa I (1994) Length and width tuning of neurons in the cat's primary visual cortex. J Neurophysiol 71:347-374. Medline

Essock EA, Haun AM, Kim YJ (2009) An anisotropy of orientation-tuned suppression that matches the anisotropy of typical natural scenes. J Vis 9(1):35.1-15. CrossRef Medline

Flevaris AV, Murray SO (2014) Orientation-specific surround suppression in the primary visual cortex varies as a function of autistic tendency. Front Hum Neurosci 8:1017. CrossRef Medline

Flevaris AV, Murray SO (2015) Feature-based attention modulates surround suppression. J Vis 15(1):15.1.29. CrossRef Medline

Flevaris AV, Martínez A, Hillyard SA (2013) Neural substrates of perceptual integration during bistable object perception. J Vis 13(13):17. CrossRef Medline

Gandhi SP, Heeger DJ, Boynton GM (1999) Spatial attention affects brain activity in human primary visual cortex. Proc Natl Acad Sci U S A 96: 3314-3319. CrossRef Medline

Gilbert CD, Wiesel TN (1990) The influence of contextual stimuli on the orientation selectivity of cells in primary visual cortex of the cat. Vision Res 30:1689-1701. CrossRef Medline

Heeger DJ (1992) Normalization of cell responses in cat striate cortex. Vis Neurosci 9:181-197. CrossRef Medline

Herrmann K, Heeger DJ, Carrasco M (2012) Feature-based attention enhances performance by increasing response gain. Vision Res 74:10-20. CrossRef Medline

Ito M, Gilbert CD (1999) Attention modulates contextual influences in the primary visual cortex of alert monkeys. Neuron 22:593-604. CrossRef Medline

Jones HE, Andolina IM, Oakely NM, Murphy PC, Sillito AM (2000) Spatial summation in lateral geniculate nucleus and visual cortex. Exp Brain Res 135:279-284. CrossRef Medline

Joo SJ, Murray SO (2014) Contextual effects in human visual cortex depend on surface structure. J Neurophysiol 111:1783-1791. CrossRef Medline

Joo SJ, Boynton GM, Murray SO (2012) Long-range, pattern-dependent contextual effects in early visual cortex. Curr Biol 22:781-786. CrossRef Medline

Kim YJ, Haun AM, Essock EA (2010) The horizontal effect in suppression: anisotropic overlay and surround suppression at high and low speeds. Vision Res 50:838-849. CrossRef Medline

Kravitz DJ, Behrmann M (2008) The space of an object: object attention alters the spatial gradient in the surround. J Exp Psychol Hum Percept Perform 34:298-309. CrossRef Medline

Kravitz DJ, Behrmann M (2011) Space-, object-, and feature-based attention interact to organize visual scenes. Atten Percept Psychophys 73: 2434-2447. CrossRef Medline

Li CY, Li W (1994) Extensive integration field beyond the classical receptive field of cat's striate cortical neurons-classification and tuning properties. Vision Res 34:2337-2355. CrossRef Medline

Li W, Piëch V, Gilbert CD (2006) Contour saliency in primary visual cortex. Neuron 50:951-962. CrossRef Medline

Marcus DS, Van Essen DC (2002) Scene segmentation and attention in primate cortical areas V1 and V2. J Neurophysiol 88:2648-2658. CrossRef Medline

Martínez A, Anllo-Vento L, Sereno MI, Frank LR, Buxton RB, Dubowitz DJ, Wong EC, Hinrichs H, Heinze HJ, Hillyard SA (1999) Involvement of striate and extrastriate visual cortical areas in spatial attention. Nat Neurosci 2:364-369. CrossRef Medline

Martinez A, Ramanathan DS, Foxe JJ, Javitt DC, Hillyard SA (2007) The role of spatial attention in the selection of real and illusory objects. J Neurosci 27:7963-7973. CrossRef Medline

Martinez-Trujillo JC, Treue S (2004) Feature-based attention increases the selectivity of population responses in primate visual cortex. Curr Biol 14:744-751. CrossRef Medline

Maunsell JH, Treue S (2006) Feature-based attention in visual cortex. Trends Neurosci 29:317-322. CrossRef Medline

McAdams CJ, Maunsell JH (2000) Attention to both space and feature modulates neuronal responses in macaque area V4. J Neurophysiol 83: 1751-1755. Medline

Müller NG, Kleinschmidt A (2003) Dynamic interaction of object- and space-based attention in retinotopic visual areas. J Neurosci 23:98129816. Medline

Murray SO (2008) The effects of spatial attention in early human visual cortex are stimulus independent. J Vis 8(10):2.1-11. CrossRef

Nassi JJ, Lomber SG, Born RT (2013) Corticocortical feedback contributes to surround suppression in V1 of the alert primate. J Neurosci 33:85048517. CrossRef Medline

Nurminen L, Angelucci A (2014) Multiple components of surround modulation in primary visual cortex: multiple neural circuits with multiple functions? Vision Res 104:47-56. CrossRef Medline

O'Craven KM, Rosen BR, Kwong KK, Treisman A, Savoy RL (1997) Voluntary attention modulates fMRI activity in human MT-MST. Neuron 18: 591-598. CrossRef Medline

Qiu FT, Sugihara T, von der Heydt R (2007) Figure-ground mechanisms provide structure for selective attention. Nat Neurosci 10:1492-1499. CrossRef Medline

Reynolds JH, Heeger DJ (2009) The normalization model of attention. Neuron 61:168-185. CrossRef Medline

Roelfsema PR, Lamme VA, Spekreijse H (1998) Object-based attention in the primary visual cortex of the macaque monkey. Nature 395:376-381. CrossRef Medline

Rossi AF, Paradiso MA (1995) Feature-specific effects of selective visual attention. Vision Res 35:621-634. CrossRef Medline

Saenz M, Buracas GT, Boynton GM (2002) Global effects of feature-based attention in human visual cortex. Nat Neurosci 5:631-632. CrossRef Medline

Sàenz M, Buraas GT, Boynton GM (2003) Global feature-based attention for motion and color. Vision Res 43:629-637. CrossRef Medline

Schoenfeld MA, Hopf JM, Martinez A, Mai HM, Sattler C, Gasde A, Heinze HJ, Hillyard SA (2007) Spatio-temporal analysis of feature-based attention. Cereb Cortex 17:2468-2477. CrossRef Medline

Schwartz O, Coen-Cagli R (2013) Visual attention and flexible normalization pools. J Vis 13(1):25. CrossRef Medline

Serences JT, Schwarzbach J, Courtney SM, Golay X, Yantis S (2004) Control of object-based attention in human cortex. Cereb Cortex 14:1346-1357. CrossRef Medline

Shih SI, Sperling G (1996) Is there feature-based attentional selection in visual search? J Exp Psychol Hum Percept Perform 22:758-779. CrossRef Medline

Shushruth S, Mangapathy P, Ichida JM, Bressloff PC, Schwabe L, Angelucci A (2012) Strong recurrent networks compute the orientation tuning of surround modulation in the primate primary visual cortex. J Neurosci 32:308-321. CrossRef Medline

Shushruth S, Nurminen L, Bijanzadeh M, Ichida JM, Vanni S, Angelucci A (2013) Different orientation tuning of near- and far-surround suppression in macaque primary visual cortex mirrors their tuning in human perception. J Neurosci 33:106-119. CrossRef Medline

Sillito AM, Grieve KL, Jones HE, Cudeiro J, Davis J (1995) Visual cortical mechanisms detecting focal orientation discontinuities. Nature 378:492496. CrossRef Medline

Snowden RJ, Hammett ST (1998) The effects of surround contrast on contrast thresholds, perceived contrast, and contrast discrimination. Vision Res 38:1935-1945. CrossRef Medline

Solomon SG, Lee BB, Sun H (2006) Suppressive surrounds and contrast gain in magnocellular-pathway retinal ganglion cells of macaque. J Neurosci 26:8715-8726. CrossRef Medline

Treue S, Martínez Trujillo JC (1999) Feature-based attention influences motion processing gain in macaque visual cortex. Nature 399:575-579. CrossRef Medline

Walker GA, Ohzawa I, Freeman RD (1999) Asymmetric suppression outside the classical receptive field of the visual cortex. J Neurosci 19:1053610553. Medline

Wannig A, Stanisor L, Roelfsema PR (2011) Automatic spread of attentional response modulation along Gestalt criteria in primary visual cortex. Nat Neurosci 14:1243-1244. CrossRef Medline

Xing J, Heeger DJ (2000) Center-surround interactions in foveal and peripheral vision. Vision Res 40:3065-3072. CrossRef Medline

Zenger-Landolt B, Heeger DJ (2003) Response suppression in V1 agrees with psychophysics of surround masking. J Neurosci 23:6884-6893. Medline

Zhang W, Luck SJ (2009) Feature-based attention modulates feedforward visual processing. Nat Neurosci 12:24-25. CrossRef Medline 